\title{
Experimental studies of hole drilling operations in stress-strain workpiecematerial
}

\author{
Vadim V. Kuts*, Mikhail S. Razumov, and Aleksandr S. Byshkin \\ South-West State University, 305040 Kursk Street 50 years of October 94, Russia
}

\begin{abstract}
Drilling holes is one of the most common operations in the part production. Consequently, increasing the efficiency of this process is an urgent task. To improve the efficiency of the drilling process, the SouthWest University developed a method of drilling for pre-stressed and prestrained workpiece material, which requires a sample to be subjected to elastic strain under load not exceeding the proportionality limit of the workpiece material. That is, when the load is removed, the dimensions of the workpiece remain unchanged. The paper presents the experimental device designed to determine the axial force and torque when drilling holes in the stress-strain workpiece material. Multi-factor experiments were carried out to obtain empirical dependences of the axial force and torque arising in drilling holes in the stress-strain workpiecematerial on the process parameters.
\end{abstract}

\section{Introduction}

Drilling holes is one of the most common operations in the part production [1-3]. Consequently, increasing the efficiency of this process is an urgent task. To improve the efficiency of the drilling process, the South-West University developed a method of drilling for pre-stressed and pre-strained workpiece material, which requires a sample to be subjected to elastic strain under load not exceeding the proportionality limit of the workpiece material. That is, when the load is removed, the dimensions of the workpiece remain unchanged [4-8]. An experimental installation has been developed to conduct an experiment to determine the influence of process parameters on the hole drilling operations in stress-strain workpiecematerial.

\section{Fundamentals of the theory}

The main part of the installation is made of two hardened plates (Fig. 1). The upper plate has a central hole that serves as a conductor, providing the drill access to the test piece. This plate also features mounting holes for dial indicators and bolts used to generate the necessary test material load The necessary load is generated by the bolts piercing the top plate screwed into the lower plate, having threaded holes. The test piece is placed in the center, between the plates. The load value is determined as follows: the test piece is placed

\footnotetext{
* Corresponding author: kuc-vadim@yandex.ru
} 
in the center of the lower plate, covered with the upper plate, which is made rest on it by gravity. The bolts are then twisted manually. The indicators are set to zero, followed by the bolts sequentially tightened by a quarter turn until all four indicators are set to a certain movement value. The indicated movement value should correspond to the limit of proportionality of the test material obtained by experiment. The elasticity is determined experimentally, thereby the table values quoted in different sources vary.

When determining the elastic limits, the test sample is placed between the fixed support platform and the movable support platform. The sample is loaded with a preliminary small load $F_{0}$ recorded by the load sensor and the position of the movable support is fixed, while the size $l_{0}$ is determined. After that, the control unit is used to feed a signal to the stepper motor, and the sample is loaded fixing the $F_{i}$ load value. The amount of displacement $\Delta_{l}$ is selected based on the required measurement accuracy. When measuring the elastic limit of the material, the load is reduced to the value equal to $F_{0}$ after the first loading and the position of the movable support is recorded, the size $l_{j}$ is determined. If the condition [9]

$$
\frac{\left|l_{0}-l_{j}\right|}{l_{0}} \geq 0,0005
$$

fails, several loading cycles are repeated, while in each cycle the movable support position is shifted by $n \cdot \Delta l$ (where $n$ is the loading cycle number) and the new load value $F_{i}$ is recorded. The loading and unloading cycles are repeated until the condition (1) is fulfilled. After this, the elastic limit value is estimated as

$$
\sigma_{u}=\frac{\left|F_{i}+F_{j-1}\right|}{2 S}
$$

where $F_{i}$ and $F_{i-1}$ - are the load values for the $i$-th and $i$-1-th loading cycles, after which the condition (1) was fulfilled; $S$ is the cross-sectional area of the sample.

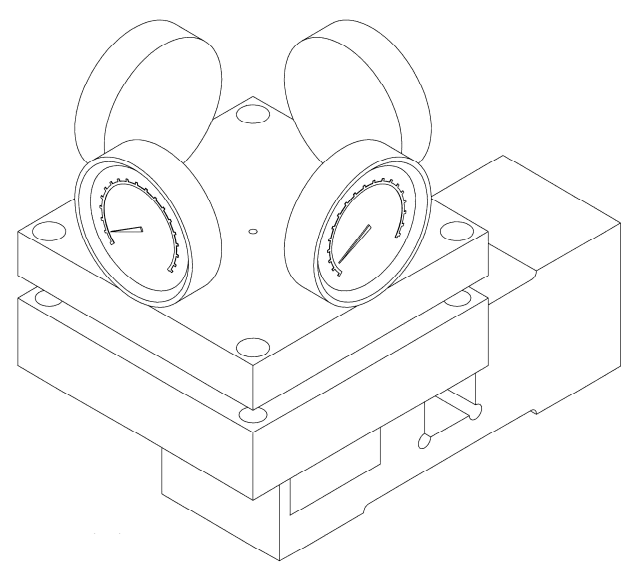

Fig.1. A part of the loading structure used to experimentally study the process of holedrilling in stress-strain workpiecematerial. 


\section{Modeling and practical implementation}

The bottom part of the plate features threaded holes used to mount the axial load sensor which is fixed in the grip of the machine as shown in Fig. 2. When determining the torque, a bearing is mounted onto the lower plate and fixed in the grip of the machine. The force sensor for the support screw screwed into the upper plate is mounted on the table of the machine by means of a stand. Then the torque $\mathrm{M}$ is calculated as follows:

$$
M=F \cdot l_{p}
$$

where $F-$ is the force registered by the sensor, $l_{p}-$ is the distance between the support screw and the center of the plate it is screwed into.

\section{Processing of experimental data}

The type $2^{3}$ full factorial experiment planning matrix was compiled for experimental purposes. This experiment planning matrix accounted for the following parameters: spindle feed and rotation frequency, the load on the sample. A standard $3 \mathrm{~mm}$ diameter spiral drill was used for drilling. processing of the experimental data allowed for the generation of the axial force - torque empirical dependences.

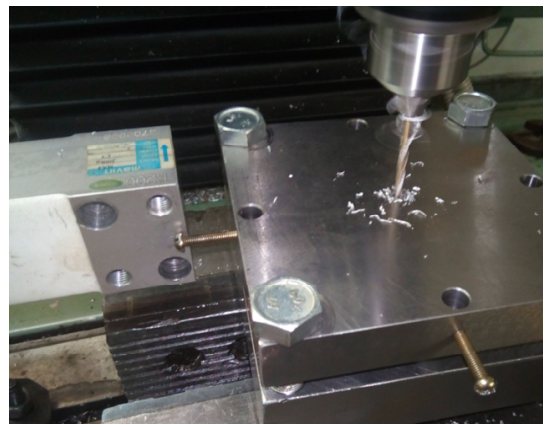

a)

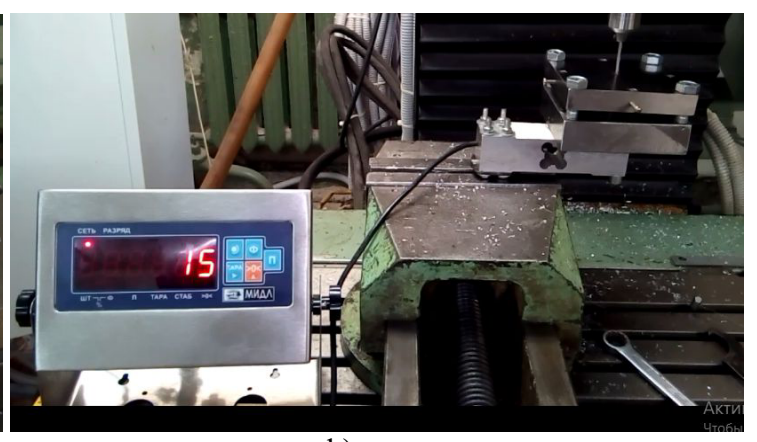

b)

Fig. 2. Fragment of the study when drilling holes in stress-strain workpiecematerial: a) torque, b) axial force.

Table 1. Experiment matrix.

\begin{tabular}{|c|c|c|c|c|c|c|c|c|c|c|c|c|}
\hline \multirow[b]{2}{*}{ № } & \multicolumn{2}{|r|}{$X_{1}$} & $X_{2}$ & \multicolumn{3}{|c|}{$x_{3}$} & \multirow[b]{2}{*}{$\begin{array}{c}M_{1}, \\
(N / m)\end{array}$} & \multirow[b]{2}{*}{$\begin{array}{c}M_{2}, \\
(N / m)\end{array}$} & \multirow[b]{2}{*}{$\begin{array}{c}M, \\
(N / m)\end{array}$} & \multirow[b]{2}{*}{$\begin{array}{l}F_{1}, \\
(k N)\end{array}$} & \multirow[b]{2}{*}{$\begin{array}{l}F_{2}, \\
(k N)\end{array}$} & \multirow[b]{2}{*}{$\begin{array}{c}F, \\
(k N)\end{array}$} \\
\hline & Код & $\begin{array}{c}S \\
\mathrm{~mm} / \mathrm{min}\end{array}$ & Код & $\begin{array}{c}V, \\
\text { min }^{-1}\end{array}$ & Код & $\begin{array}{c}L, \\
\mathrm{~mm}\end{array}$ & & & & & & \\
\hline 1 & - & 10 & - & 80 & - & 0,1 & 0,168 & 0,189 & 0,179 & 105,912 & 109,834 & 107,873 \\
\hline 2 & + & 80 & - & 80 & - & 0,1 & 1,936 & 2,011 & 1,974 & 205,940 & 186,326 & 196,133 \\
\hline 3 & - & 10 & + & 800 & - & 0,1 & 0,326 & 0,360 & 0,343 & 37,461 & 39,030 & 38,246 \\
\hline 4 & + & 80 & + & 800 & - & 0,1 & 0,251 & 0,271 & 0,261 & 73,060 & 74,040 & 73,550 \\
\hline 5 & - & 10 & - & 80 & + & 0,6 & 0,106 & 0,110 & 0,108 & 95,124 & 101,008 & 98,066 \\
\hline 6 & + & 80 & - & 80 & + & 0,6 & 0,587 & 0,608 & 0,598 & 166,713 & 186,326 & 176,520 \\
\hline 7 & - & 10 & + & 800 & + & 0,6 & 0,154 & 0,161 & 0,158 & 29,420 & 33,343 & 31,372 \\
\hline 8 & + & 80 & + & 800 & + & 0,6 & 0,185 & 0,199 & 0,192 & 62,763 & 66,685 & 64,724 \\
\hline
\end{tabular}




$$
\begin{aligned}
& M=0,093 \cdot \frac{S^{0,494}}{V^{0,231} \cdot L^{0,39}} \\
& F=318 \cdot \frac{S^{0,315}}{V^{0,455} \cdot L^{0,075}}
\end{aligned}
$$

where $S$ - feeds, $V$ - spindle feed, $L$ - load on the sample.

\section{Discussion of the data}

Thus, the data analysis allows for the conclusion that during hole drilling in stress-strain material the axial force decreases by $10 \%$ and the twisting moment decreases by $30 \%$ and more.

Herewith, according to authors of the article [10] normal drills of $10 \mathrm{~mm}$ and more in diameter are not exposed to the fracture risk caused by the excessive twisting moment as with these drills the max stresses arising in the drills are usually limited by the dulling speed as the cutting and feeding speeds increase. For drills with the diameter under $10 \mathrm{~mm}$, it is recommended to calculate the twisting moment as follows:

$$
M=0,00867 D^{2}
$$

to maintain the tool integrity.

Equating these formulas allows for the calculation of maximum possible feeds for small diameter drills during drilling the given material.

\section{Conclusion}

Thus it may be concluded that for the drills of under $10 \mathrm{~mm}$ in diameter the decrease of twisting moment by $30 \%$ shall allow the feeding increase of up to $30 \%$. Feeding increase of up to $30 \%$ consequently increases the process productivity that makes the hole drilling operations in stress-strain material more efficient compared to conventional drilling operations.

The study was carried out within the framework of funding scholarship of the President of the Russian Federation to postdoctoral researchers and postgraduate students performing advanced research-and-development activities in the priority fields for the modernization of the Russian economy for 2018-2020 SP-591.2018.1

\section{References}

1. M. S. Razumov, V. V. Sidorova, A. N. Grechukhin, MMI, 5, 19 (2014)

2. S.G. Emel'yanov, V.V. Sidorova, V.V. Ponomarev, M.S. Razumov, Chemical and Petroleum Engineering, 52 (11-12), 796 (2017)

3. V. Maslennikov, S. A. Chevychelov, V. V. Sidorova, et al., Izv. Yugo-Zapad. Gos. Univ. Ser. Tekhn. Tekhnol., 2, 1, 117 (2012)

4. M. S. Razumov, P. A. Ponkratov, Patent 147317 RF, 2014120738/02, publ. 11.10.2014

5. V. V. Sidorova, M. S. Razumov, Fund. Prikl. Probl. Tekhn. Tekhnol., 4 (306), 51 (2014)

6. V. V. Sidorova, M. S. Razumov, Innovations in Science, Processes, and Technologies: Proc. All-Russ. Sci. Techn. Conf., Izhevsk State Techn. Univ., 242 (2014) 
7. A. V. Maslennikov, S. A. Chevychelov, I. G. Golubev, Russian Engineering Research, 33 (5), 295 (2013)

8. A. V. Maslennikov, S. A. Chevychelov, M. S. Merzhoeva, M. S. Gatiev, V. V. Sidorova, Russian Engineering Research, 34 (11), 722 (2014)

9. V. V. Kuts, M. S. Razumov, A. S. Byshkyn, O. I. Drynovam, Innovation, quality and service in engineering and technology a Collection of scientific papers of 7 th International scientific-practical conference, 216 (2017)

10. The calculation of cutting conditions when drilling, deployment http://проминструмент.pф/index.php/rezhim/54-sverl (circulation date: 17.03.18). 